\title{
Safety concerns of lead chromate in enamel paints: A study based on the Sri Lankan enamel paints industry after the lead paint regulatory enforcement
}

\author{
MC Lakmini" and KRR Mahanama \\ Department of Chemistry, Faculty of Science, University of Colombo, Colombo 03.
}

\begin{abstract}
Although lead $(\mathrm{Pb})$ paint testing has been carried out in a large number of studies in Sri Lanka, little work appears to have been done to investigate the chromium $(\mathrm{Cr})$ levels, variation of $\mathrm{Pb}$ and $\mathrm{Cr}$ levels through different production batches of paint manufacturers and the possible sources of unusually higher $\mathrm{Pb}$ and $\mathrm{Cr}$ levels in paints. Thirty-six enamel paints manufactured after the lead paint regulatory enforcement, were randomly purchased from six popular brands in Sri Lanka to assess their $\mathrm{Pb}$ and $\mathrm{Cr}$ levels. Heavy metals in liquid paints were acid digested for the analysis by flame atomic absorption spectrometry (FAAS). From the thirty-six paints analysed (six colours from six brands) one yellow and one green paint showed highest $\mathrm{Pb}$ and $\mathrm{Cr}$ levels. Reported $\mathrm{Pb}$ levels in yellow and green paints were $11545 \pm 6 \mathrm{ppm}$ and $4060 \pm 9 \mathrm{ppm}$ and Cr levels were $2681 \pm 2 \mathrm{ppm}$ and $960 \pm 7$ ppm, respectively. These yellow and green paints were labelled as safe although they exceeded the $\mathrm{Pb}$ regulatory limit. $\mathrm{Pb}$ and $\mathrm{Cr}$ in the other 34 samples were below Sri Lankan regulatory limits. For paints with both $\mathrm{Pb}$ and $\mathrm{Cr}, \mathrm{Pb}$ and $\mathrm{Cr}$ mole ratio was 1.079:1, suggesting the possible presence of lead chromate $\left(\mathrm{PbCrO}_{4}\right)$ in certain paints although the manufactured paints adhered to safety standards. Batch-wise manufacturing variation was also reported. Thus, formulation of national policies and their proper implementation is necessary for manufacturing safe paints in Sri Lanka.
\end{abstract}

Keywords: Chromium, government regulations, lead, lead chromate, yellow and green enamel paints.

\section{INTRODUCTION}

Heavy metals are considered to be one of the globally distributed priority pollutants because of their toxicity, persistence in nature, and ability to be incorporated into food chains (Jha et al., 2016). Deteriorated residential paints are one of the most common sources of heavy metals in the environment and the resulting issue is a global matter of concern (Meyer et al., 2008). Paints contain not only $\mathrm{Pb}$ but also other heavy metals such as chromium $(\mathrm{Cr})$, cadmium $(\mathrm{Cd})$, nickel $(\mathrm{Ni})$ and zinc (Zn) (Oligo et al., 2017). In the priority list of hazardous substances, $\mathrm{Pb}$ is ranked second and $\mathrm{Cr}$ ranked seventeenth by Agency for Toxic Substances and Disease Registry (ATSDR, 2013). $\mathrm{Pb}$ has no function in the human body and is a carcinogenic heavy metal (ATSDR, 2020). Health authorities have concluded that there is no threshold value for the blood $\mathrm{Pb}$ level below which its concentration can be considered safe (Wani et al., 2015). Toxicity of $\mathrm{Cr}$ is dependent upon the oxidation state and the solubility. $\mathrm{Cr}$ (III) has very low human toxicity, whereas exposure to high levels of $\mathrm{Cr}(\mathrm{VI})$ can produce a variety of acute and chronic effects although $\mathrm{Cr}$ is necessary for humans in minute amounts (ATSDR, 2012).

\footnotetext{
*Corresponding author (lakmini.chem.uoc@gmail.com; (iD https://orcid.org/0000-0002-9505-5332)
} 
Enamel paints are used frequently for household decoration and paints with high $\mathrm{Pb}$ and $\mathrm{Cr}$ levels still continue to be sold in Sri Lanka without considering the government regulations as has been documented by a number of investigators (Rubesinghe et al., 2013; 2015; Rathnamalala et al., 2015). When houses with paints containing heavy metals such as $\mathrm{Pb}$ and $\mathrm{Cr}$ deteriorate or are remodelled without taking proper heavy metal controlling precautions, the heavy metals can become available in dust and soil. These contaminated dust and soil are often the most significant sources of human exposure while children are the most vulnerable group. (WHO, 1995; Meyer et al., 2008; Hossain et al., 2013). Children's bodies are more rapidly growing and developing, thus sustainable permanent damages can occur if toxic exposures occur during critical growth stages (WHO, 2010). Painters are also vulnerable to heavy metals exposure because more significant exposure can result due to airborne fine particles during painting activities contributing to severe health problems (Brosché et al., 2014).

Large number of scientific studies on $\mathrm{Pb}$-based paints have been carried out globally because the exposure to $\mathrm{Pb}$ is a growing global public health concern. Most of the scientific literature revealed that the production and trade of $\mathrm{Pb}$-based paints are still widespread globally and that $\mathrm{Pb}$-based paints are still widely used in many low and middle-income developing countries (Connora et al., 2018). According to the World Health Organization data in 2017, human exposure to $\mathrm{Pb}$ accounted for 1.06 million deaths and 24.4 million years of healthy life lost (disability-adjusted life years) worldwide due to long-term effects on health while the highest burden has been reported in low- and middle-income developing countries (WHO, 2017).

In response to concerns over the continued use of $\mathrm{Pb}$ in paints, their use has been restricted by government regulations of most of the countries (CPSIA, 2008; Kumar \& Gottesfeld, 2008; PDENR, 2013; NEA, 2014). Decades earlier the International Labour Organization publicised a convention on the prohibition of the use of $\mathrm{Pb}$-based compounds in residential paints (ILO, 1921). Sri Lanka consumer affairs authority has also stated by a gazette notification that the $\mathrm{Pb}$ in enamel paints should not exceed 600 milligrams per kilogram $\left(\mathrm{mgkg}^{-1}\right)$ and the regulation was come into the effect on 2013 January 01 (CAA, 2011).

It is well known that $\mathrm{Pb}$ has been intentionally added to paints as $\mathrm{Pb}$ pigments, drying agents, and as anticorrosive agents or they may present as impurities from raw materials. The commonly used $\mathrm{Pb}$ pigments include lead chromate, lead oxide, lead molybdate, and lead sulphate. Paints often contain driers such as lead octoate which make paints dry faster. $\mathrm{Pb}$ compounds such as lead tetroxide are also added to the paints used on metal surfaces to inhibit rust or corrosion. Fillers and other ingredients used in the manufacturing of paints may contribute $\mathrm{Pb}$ to the paint as contaminants. However, there are readily available non-hazardous substitutes for all $\mathrm{Pb}$ compounds including titanium dioxide, barium sulfate, and silicon or aluminum oxides worldwide.

Chromium has also been intentionally added as $\mathrm{Cr}$ pigments and they may also be present as impurities from raw materials. The most commonly used chrome yellow pigment is lead chromate $\left(\mathrm{PbCrO}_{4}\right)$. Lead chrome greens $\left[\mathrm{PbCrO}_{4}: \mathrm{KFe}\left(\mathrm{Fe}(\mathrm{CN})_{6}\right)\right]$ are also added as green pigments. Chromium oxide $\left(\mathrm{Cr}_{2} \mathrm{O}_{3}\right)$ is a dull green inorganic pigment which is also used in all types of paints (Abel, 1999; Kumar \& Gottesfeld, 2008; Gupta \& Gauri, 2013; IPEN, 2014).

$\mathrm{PbCrO}_{4}$ is a relatively inexpensive yellow inorganic pigment which was extensively used in the paint industry. Intentional additions of metallic raw material (e.g. $\mathrm{PbCrO}_{4}$ impurities present in raw materials or contaminations during paint manufacturing process are the possible sources of these metals into consumer paints (UNEP \& WHO, 2011; IPEN, 2014). Although the global paint industry is growing rapidly with expanding economy, most recent influences on paint developments are related to environmental considerations and need to strictly adhere to health and safety legislations (Shim et al., 2011). There is therefore an urgent need to ensure that paints are manufactured using only non-hazardous materials.

In Sri Lanka, the awareness on public health impact of exposure to $\mathrm{Pb}$ in enamel paints is continuously growing, but relatively no attention has been devoted to assess the batch-wise variations of hazardous metal levels in enamel paints within a year. A large number of research studies have carried out on $\mathrm{Pb}$ levels in enamel paints, but there is lack of data for $\mathrm{Cr}$ levels in enamel paints although there is a mandatory restriction on the $\mathrm{Cr}$ level in enamel paints (SLSI, 2010).

This investigation was designed to help fill the gaps in knowledge of $\mathrm{Pb}$ and $\mathrm{Cr}$ levels in enamel paints. It is focused on the investigation of consistency of $\mathrm{Pb}$ and $\mathrm{Cr}$ levels with regulatory standards, possible sources of unusually higher $\mathrm{Pb}$ and $\mathrm{Cr}$ levels in paints and finally to make recommendations to stop the use of hazardous compounds in manufacturing paints. 


\section{METHODOLOGY}

\section{Selection of samples}

In this study, purposive random sampling of enamel paints ready for sale in retail shops in Colombo district, Sri Lanka was done. The selection of enamel paint brands and the colours were based upon the results of a questionnaire survey carried out among randomly selected paint uses and retailers.

\section{Collection of samples}

All the samples subjected to the analysis were collected during the period from November 2014 to April 2015 having being manufactured between 2014 January and 2015 April, after the $\mathrm{Pb}$ paint regulation came into effect. The selected paint brands are controlling $97 \%$ of the paint market share in Sri Lanka. These manufactures have also indicated that they are in the process of eliminating the use of hazardous compounds in enamel paints or have eliminated (Rathnamalala, 2015; Rubasinghe, 2015).

A total of thirty-six enamel paint samples $(n=36)$ from six colours (red, yellow, white, black, brown, and, green) of six brands, hereafter named as A, B, C, D, E, and $\mathrm{F}$, were collected. On the analysis revealing that one yellow paint manufactured on 2014 March 27 and one green paint manufactured on 2014 January 13 by two manufactures (Brands $\mathrm{A}$ and $\mathrm{B}$ ) reported the highest $\mathrm{Pb}$ and $\mathrm{Cr}$ levels, analyses were repeated for ten samples of those two particular paints. Five samples from the same batch which contained highest $\mathrm{Pb}$ and $\mathrm{Cr}$ levels and five samples from different batches were purchased from different locations and analysed.

\section{Reagents and materials}

All the reagents used were prepared from analytical grade chemicals. All solutions were prepared in double distilled water. Nitric acid ( $\geq 70 \%$, Sigma Aldrich), sulphuric acid ( $\geq 98 \%$, Sigma Aldrich) ammonium acetate ( $\geq 99 \%$, Fluka), potassium permanganate $(\geq 99 \%$, Fluka) and hydroxylamine hydrochloride $(\geq 99 \%$, Fluka) were used for sample digestion. Lead chromate $(\geq 98 \%$, Sigma Aldrich) was used for the recovery analysis of $\mathrm{Pb}$ and Cr. All the plastic and glassware were cleaned by soaking overnight in $\mathrm{HNO}_{3}$ solution $(5 \% \mathrm{v} / \mathrm{v})$ and then rinsed with double distilled water before use.

Lead standard stock solution (1000 $\left.\mathrm{mgkg}^{-1}\right)$ was prepared by dissolving $0.162 \mathrm{~g}$ of $\mathrm{Pb}\left(\mathrm{NO}_{3}\right)_{2}(\geq 99.0 \%$, Sigma Aldrich) in $1 \mathrm{~mL}$ of water, then adding $1 \mathrm{~mL}$ of
$\mathrm{HNO}_{3}$ and diluting to $100 \mathrm{~mL}$ with water. Chromium standard stock solution $\left(1000 \mathrm{mgkg}^{-1}\right)$ was prepared by dissolving $0.377 \mathrm{~g}$ of $\mathrm{K}_{2} \mathrm{CrO}_{4}(\geq 99 \%$, Sigma Aldrich) in $10 \mathrm{~mL}$ of water and diluting to $100 \mathrm{~mL}$. The working solutions of each metal were prepared daily by serial dilutions of the stock solutions with double distilled water prior to the analysis. The linear dynamic range of each metal determined was $2.0-10.0 \mathrm{ppm}$.

\section{Instrumentation}

An oven (Thermo Scientific, US) capable of maintaining temperature of $110 \pm 5{ }^{\circ} \mathrm{C}$ was used for evaporating solvents from paint samples. An electric muffle furnace (Advantec EL 280) capable of maintaining temperature from $450{ }^{\circ} \mathrm{C}$ to $550{ }^{\circ} \mathrm{C}$ was used for ashing the charred paint samples. A hot plate $\left(\mathrm{IKA}^{\circledR} \mathrm{RH}\right.$ basic 1$)$ capable of maintaining surface temperature from $70{ }^{\circ} \mathrm{C}$ to $200{ }^{\circ} \mathrm{C}$ was used for sample charring and acid digestions.

All measurements were carried out with a $932 \mathrm{AB}$ Plus model flame atomic absorption spectrophotometer (GBC Scientific Ltd., Canada). The instrumental parameters were adjusted according to the manufacturers' recommendations. A lead hollow cathode lamp was used as the radiation source for determination of $\mathrm{Pb}$ and the wavelength was set at $283.3 \mathrm{~nm}$ resonance line. The air acetylene flame was used. A chromium hollow cathode lamp was used as the radiation source for determination of $\mathrm{Cr}$ and the wavelength was set at $357.9 \mathrm{~nm}$ resonance line. The nitrous oxide - acetylene flame was used.

\section{Sample preparation, analysis and quality control}

Samples were prepared for the analysis of $\mathrm{Pb}$ and $\mathrm{Cr}$ according to ASTM D 3335-85a: 2009 (ASTM, 2009) and ASTM D 3718-85a:2010 (ASTM, 2010), respectively. The analysis was conducted on liquid coatings. The liquid paint samples were mixed thoroughly in a can using a clean single-use stirrer until homogeneous and a representative paint sample was drawn for the analysis. An aliquot of the representative paint sample was initially charred on a hot plate to remove solvents. The charred sample was then ashed at $475-500{ }^{\circ} \mathrm{C}$ in a muffle furnace for $2 \mathrm{~h}$. For the analysis of $\mathrm{Pb}$, ashed samples were digested with $20 \mathrm{~mL}$ of $50 \%(\mathrm{v} / \mathrm{v}) \mathrm{HNO}_{3}$ on the hot plate. The resulted solution was filtered through a Whatman No.1 filter paper into a $50 \mathrm{~mL}$ volumetric flask and washed with ammonium acetate solution, then the volume was adjusted to $50 \mathrm{~mL}$. The digestion of an ashed sample for $\mathrm{Cr}$ content was carried out with $10 \mathrm{~mL}$ of a mixture of $0.2 \mathrm{~g} \mathrm{KMnO}_{4}$ in $100 \mathrm{~mL}$ of $50 \%$ (v/v) $\mathrm{H}_{2} \mathrm{SO}_{4}$ in an acid decomposition vessel at $105{ }^{\circ} \mathrm{C}$ 
for $1 \frac{1}{2}$ hours. Then the contents were filtered through a Whatman No.1 filter paper into a $50 \mathrm{~mL}$ volumetric flask. Hydroxylamine hydrochloride solution was added dropwise to the filtrate until the permanganate colour has been discharged, then diluted to volume with distilled water. Paint samples were analysed using flame atomic absorption spectrophotometer after the digestions and dilutions. Five replicates of the same sample were digested and analysed to calculate the mean value. The absorbance values of sample solutions were measured against the blank solution. The difference between the absorbance of the samples and blank solutions at respective wavelengths was used as the analytical parameter for quantifications. Calibration curves were constructed by plotting the analytical signal versus the metal ion concentration in a series of working standards prepared in the range of $2.0-10.0 \mathrm{ppm}$.

The accuracy of the methods was evaluated by percent recovery of $\mathrm{Pb}$ and $\mathrm{Cr}$. White paint of brand $\mathrm{D}$ found to contain no detectable levels of $\mathrm{Pb}$ and $\mathrm{Cr}$ was spiked with 156 ppm, 468 ppm, and 935 ppm of $\mathrm{PbCrO}_{4}$ for the recovery analysis. Repeatability of analysis was expressed in terms of standard deviation. Limit of detection of instrument for each metal was determined using a statistical approach. Ten blank samples fortified at lowest acceptable concentration were digested and analysed by FAAS to calculate the limit of detection (LOD) at respective wavelengths of each metal ion. The LOD was calculated as $3 \mathrm{~s}+$, where, $\mathrm{s}=$ standard deviation for the blanks fortified with known amount of standard solution and = mean measured value of blank samples. The calculated LOD values of $\mathrm{Pb}$ and $\mathrm{Cr}$ was 5.4 ppm and 5.8 ppm per dry weight of the paint, respectively.

$\mathrm{Pb}$ and $\mathrm{Cr}$ levels in non-volatile portion of the liquid paints were expressed in parts per million (ppm) on the dry weight of the paint and results were presented as arithmetic means \pm standard deviation of five replicates. Rejection of outliers' test/Q-test was employed at $95 \%$ confidence limit to take decisions if any outlying experimental data are available.

\section{RESULTS AND DISCUSSION}

\section{$\mathrm{Pb}$ levels in analysed paint samples}

Total $\mathrm{Pb}$ level in ppm in enamel paints was compared by brand and colour to assess their compliance with national and international regulatory standards. The $\mathrm{Pb}$ levels of $90 \mathrm{ppm}$ and $600 \mathrm{ppm}$ were chosen because $600 \mathrm{ppm}$ on dry weight is the current regulatory limit of $\mathrm{Pb}$ in enamel paints in Sri Lanka (CAA, 2011) and in some other countries, e.g., Singapore and China (Clark et al., 2009) while 90 ppm on dry weight of paints is the current regulatory limit in the United States (CPSIA, 2008), Philippines (PDENR, 2013), Nepal (Gottesfeld et al., 2014) and India (Kumar \& Gottesfeld, 2008). Data on individual samples are presented in Table 1.

Table 1 summarizes the $\mathrm{Pb}$ levels in 36 paint samples analysed in this study. Only two samples had the $\mathrm{Pb}$ levels greater than $600 \mathrm{ppm}$. Yellow paint from brand A (A-Yellow) was nearly 20 times greater while the green paint from brand B (B-Green) was 7 times greater than the Sri Lankan standards. Altough $\mathrm{Pb}$ levels in these two paints exceeded the current regulatory limit, A-Yellow paint was labelled as 'SLS 539' and B-Green paint as 'Lead safe' which violate the government regulations. In addition to these two samples, six other samples exceeded the US regulatory limit of $90 \mathrm{ppm}$. Interestingly, four out of the eight samples exceeded US standard were yellow paints, two were green paints, one red paint and one brown paint. Rest of the samples are safer in terms of Sri Lankan and US standards.

Table 1: Mean Pb levels of six different colours of six different brands

\begin{tabular}{ccccccc}
\hline \multirow{2}{*}{ Brand } & \multicolumn{5}{c}{ Pb level ( \pm standard deviation of five replicates $)$ ppm on dry weight } \\
& White & Black & Yellow & Red & Green & Brown \\
\hline A & $<5.4$ & $<5.4$ & $11545 \pm 6$ & $<5.4$ & $96 \pm 1$ & $<5.4$ \\
B & $36 \pm 3$ & $<5.4$ & $366 \pm 2$ & $97 \pm 0.8$ & $4060 \pm 9$ & $204 \pm 1$ \\
C & $23 \pm 2$ & $<5.4$ & $156 \pm 1$ & $25 \pm 2$ & $53 \pm 2$ & $38 \pm 5$ \\
D & $<5.4$ & $<5.4$ & $<5.4$ & $<5.4$ & $19 \pm 4$ & $58 \pm 3$ \\
E & $22 \pm 3$ & $21 \pm 5$ & $98 \pm 2$ & $18 \pm 3$ & $19 \pm 2$ & $22 \pm 2$ \\
F & $41 \pm 4$ & $56 \pm 2$ & $46 \pm 3$ & $48 \pm 3$ & $47 \pm 1$ & $44 \pm 3$ \\
\hline
\end{tabular}

Limit of detection of $\mathrm{Pb}=5.4 \mathrm{ppm}$ 


\section{Cr levels in analysed paint samples}

Total $\mathrm{Cr}$ level in ppm in analysed samples were compared by brand and colour to assess their compliance with regulatory limit in Sri Lanka. According to the specifications for enamel paints made by the Sri Lanka Standards Institution, the maximum permissible $\mathrm{Cr}$ content in enamel paints is $250 \mathrm{ppm}$ on dry weight of paints (SLSI, 2010). Data on individual samples are presented in Table 2.

Table 2: $\quad$ Mean $\mathrm{Cr}$ levels of six different colours of six different brands

\begin{tabular}{ccccccc}
\hline \multirow{2}{*}{ Brand } & \multicolumn{5}{c}{ Cr level $( \pm$ standard deviation of five replicates), ppm on dry weight } \\
& White & Black & Yellow & Red & Green & Brown \\
\hline A & $<5.8$ & $<5.8$ & $2681 \pm 2$ & $<5.8$ & $19 \pm 4$ & $<5.8$ \\
B & $<5.8$ & $<5.8$ & $83 \pm 5$ & $<5.8$ & $960 \pm 7$ & $42 \pm 3$ \\
C & $<5.8$ & $<5.8$ & $<5.8$ & $<5.8$ & $<5.8$ & $<5.8$ \\
D & $<5.8$ & $<5.8$ & $<5.8$ & $<5.8$ & $<5.8$ & $<5.8$ \\
E & $<5.8$ & $<5.8$ & $<5.8$ & $<5.8$ & $<5.8$ & $<5.8$ \\
F & $<5.8$ & $<5.8$ & $<5.8$ & $<5.8$ & $<5.8$ & $<5.8$ \\
\hline
\end{tabular}

Limit of detection of $\mathrm{Cr}=5.8 \mathrm{ppm}$

Only five samples had detectable levels of $\mathrm{Cr}$ and all of them were manufactured by brands $\mathrm{A}$ and $\mathrm{B}$. In addition to the yellow and green samples from both brands, brown sample from brand $\mathrm{B}$ had detectable levels of $\mathrm{Cr}$. Out of the 36 samples, only two samples exceeded the Sri Lankan regulatory standard and these two samples had reported high $\mathrm{Pb}$ levels as well.

Both $\mathrm{Pb}$ and $\mathrm{Cr}$ were detected in only five paint samples from all the paints analysed (A-Yellow, A-Green, $\mathrm{B}-$ Yellow, B-Green, B-Brown). The origin of $\mathrm{Pb}$ and $\mathrm{Cr}$ in the paints was investigated.

For the five samples with $\mathrm{Pb}$ and $\mathrm{Cr}$ present, the correlation between the number of millimoles of $\mathrm{Pb}$ and $\mathrm{Cr}$ was investigated (Figure 1).

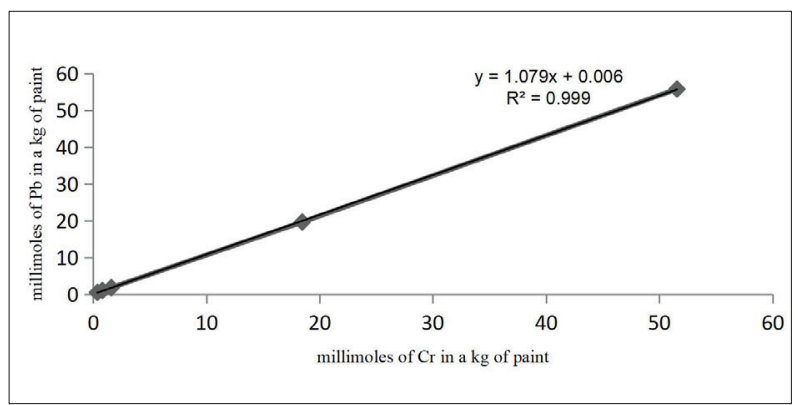

Figure 1: Variation of millimoles of $\mathrm{Pb}$ in a $\mathrm{kg}$ of paint vs millimoles of $\mathrm{Cr}$ in a $\mathrm{kg}$ of paint
As shown in Figure 1 there is a linear relationship between millimoles of $\mathrm{Pb}$ and millimoles of $\mathrm{Cr}$ in a $\mathrm{kg}$ of paint where the ratio of millimoles of $\mathrm{Pb}$ to millimoles of $\mathrm{Cr}$ in a $\mathrm{kg}$ of paint is 1.079 , suggesting $\mathrm{Pb}$ and $\mathrm{Cr}$ may be present in the form of $\mathrm{PbCrO}_{4}$.

Since $\mathrm{PbCrO}_{4}$ is insoluble, the recovery of $\mathrm{Pb}$ and $\mathrm{Cr}$ from a $\mathrm{PbCrO}_{4}$ spiked paint sample was determined. Since D-White paint has no detectable levels of $\mathrm{Pb}$ and $\mathrm{Cr}$, it was selected as the base material and spiked with a known amount of $\mathrm{PbCrO}_{4}(935 \mathrm{ppm})$, such that the recovered $\mathrm{Pb}$ and $\mathrm{Cr}$ levels be approximately $600 \mathrm{ppm}$ and $150 \mathrm{ppm}$. The analysis was replicated five times.

Table 3 presents the $\mathrm{Pb}$ and $\mathrm{Cr}$ recovery from $\mathrm{PbCrO}_{4}$ spiked paint sample.

Table 3: $\mathrm{Pb}$ and $\mathrm{Cr}$ levels of $\mathrm{PbCrO}_{4}$ spiked paint sample (D-White paint spiked at $935 \mathrm{ppm} \mathrm{PbCrO}_{4}$ )

\begin{tabular}{cccccc}
\hline Trial & \multicolumn{2}{c}{ Recovered } & \multicolumn{2}{c}{ Recovered amounts in } & Mole ratio \\
& concentration $(\mathrm{ppm})$ & \multicolumn{2}{c}{$10^{-3}$ moles kg- $^{-1}$} & \\
& $\mathrm{~Pb}$ & $\mathrm{Cr}$ & $\mathrm{n}_{\mathrm{Pb}}$ & $\mathrm{n}_{\mathrm{Cr}}$ & $\mathrm{n}_{\mathrm{Pb} / \mathrm{Cr}} \mathrm{n}_{\mathrm{Cr}}$ \\
\hline 1 & 598 & 148 & 2.89 & 2.85 & 1.01 \\
2 & 601 & 151 & 2.90 & 2.90 & 1.00 \\
3 & 599 & 149 & 2.89 & 2.86 & 1.01 \\
4 & 598 & 149 & 2.89 & 2.86 & 1.01 \\
5 & 599 & 152 & 2.89 & 2.92 & 0.989 \\
\hline
\end{tabular}

$\mathrm{n}_{\mathrm{Pb}}$ - number of moles of $\mathrm{Pb} ; \mathrm{n}_{\mathrm{Cr}}$ - number of moles of $\mathrm{Cr}$ 
As shown in Table 3, it is clear that if $\mathrm{PbCrO}_{4}$ is present in the paint samples it can be quantified with sufficient accuracy and precision.

\section{Investigation of batchwise variations of $\mathrm{Pb}$ and $\mathrm{Cr}$ levels in selected paints}

As shown in Tables 1 and 2, A-Yellow paint which was manufactured on 2014 March 27and B-Green paint which was manufactured on 2014 January 13 contained excessive levels of $\mathrm{Pb}$ and $\mathrm{Cr}$. Therefore, batchwise variations of $\mathrm{Pb}$ and $\mathrm{Cr}$ levels in the different production batches of A-Yellow and B-Green paints was investigated. Five samples from same batch of each colour were purchased from different locations and results were found to be consistent for both $\mathrm{Pb}$ and $\mathrm{Cr}$. $\mathrm{Pb}$ and $\mathrm{Cr}$ levels in paints of five different batches of each colour purchased from different locations were below regulatory limits, Tables 4 and 5 .

For the five A-Yellow paints manufactured on 2014/03/27 and the five B-Green paints manufactured on 2014/01/13, the Q statistical test was performed at $95 \%$ confidence limit (Qcritical for 5 determinants at $95 \%$

Table 4: $\quad \mathrm{Pb}$ and $\mathrm{Cr}$ levels of different manufacturing batches of A-Yellow enamel paints

\begin{tabular}{lcccc}
\hline Sample No & $\begin{array}{c}\text { Manufactured } \\
\text { date }\end{array}$ & $\begin{array}{c}{[\mathrm{Pb}], \mathrm{ppm} \text { on }} \\
\text { dry weight }\end{array}$ & $\begin{array}{c}{[\mathrm{Cr}], \text { ppm on dry }} \\
\text { weight }\end{array}$ & $\mathrm{n}_{\mathrm{Pb}} / \mathrm{n}_{\mathrm{Cr}}$ ratio \\
\hline A-Yellow 1 & $2014 / 01 / 08$ & $<5.4$ & $96 \pm 2$ & - \\
A-Yellow 2 & $2014 / 02 / 03$ & $<5.4$ & $<5.8$ & - \\
A-Yellow 3 & $2014 / 03 / 21$ & $12 \pm 1$ & $<5.8$ & - \\
A-Yellow 4 & $2014 / 03 / 27$ & $11545 \pm 6$ & $2681 \pm 2$ & 1.082 \\
A-Yellow 5 & $2014 / 03 / 27$ & $11528 \pm 4$ & $2657 \pm 9$ & 1.090 \\
A-Yellow 6 & $2014 / 03 / 27$ & $11534 \pm 5$ & $2698 \pm 7$ & 1.074 \\
A-Yellow 7 & $2014 / 03 / 27$ & $11552 \pm 7$ & $2682 \pm 8$ & 1.082 \\
A-Yellow 8 & $2014 / 03 / 27$ & $11516 \pm 9$ & $2695 \pm 6$ & 1.073 \\
A-Yellow 9 & $2014 / 08 / 16$ & $<5.4$ & $<5.8$ & - \\
A-Yellow 10 & $2015 / 01 / 02$ & $8 \pm 1$ & $<5.8$ & - \\
\hline
\end{tabular}

Limit of detection of $\mathrm{Pb}=5.4 \mathrm{ppm}$; limit of detection of $\mathrm{Cr}=5.8 \mathrm{ppm} ; \mathrm{n}_{\mathrm{Pb}}-$ number of moles of $\mathrm{Pb} ; \mathrm{n}_{\mathrm{Cr}}-$ number of moles of $\mathrm{Cr}$

Table 5: $\mathrm{Pb}$ and $\mathrm{Cr}$ levels of different manufacturing batches of B-Green enamel paints

\begin{tabular}{lcccc}
\hline Sample No & $\begin{array}{c}\text { Manufactured } \\
\text { date }\end{array}$ & $\begin{array}{c}{[\mathrm{Pb}], \text { ppm on }} \\
\text { dry weight }\end{array}$ & $\begin{array}{c}{[\mathrm{Cr}], \text { ppm on }} \\
\text { dry weight }\end{array}$ & $\mathrm{n}_{\mathrm{Pb}} / \mathrm{n}_{\mathrm{Cr}}$, ratio \\
\hline B-Green 1 & $2014 / 01 / 13$ & $4060 \pm 9$ & $960 \pm 7$ & 1.062 \\
B-Green 2 & $2014 / 01 / 13$ & $4097 \pm 6$ & $956 \pm 6$ & 1.077 \\
B-Green 3 & $2014 / 01 / 13$ & $4088 \pm 7$ & $974 \pm 8$ & 1.054 \\
B-Green 4 & $2014 / 01 / 13$ & $4074 \pm 5$ & $968 \pm 6$ & 1.057 \\
B-Green 5 & $2014 / 01 / 13$ & $4096 \pm 4$ & $980 \pm 3$ & 1.050 \\
B-Green 6 & $2014 / 08 / 11$ & $<5.4$ & $<5.8$ & - \\
B-Green 7 & $2014 / 12 / 20$ & $<5.4$ & $6 \pm 1$ & - \\
B-Green 8 & $2015 / 01 / 03$ & $<5.4$ & $<5.8$ & - \\
B-Green 9 & $2015 / 01 / 13$ & $<5.4$ & $<5.8$ & - \\
B-Green 10 & $2015 / 01 / 27$ & $<5.4$ & $<5.8$ & - \\
\hline
\end{tabular}

Limit of detection of $\mathrm{Pb}=5.4 \mathrm{ppm}$; limit of detection of $\mathrm{Cr}=5.8 \mathrm{ppm} ; \mathrm{n}_{\mathrm{Pb}}$ - number of moles of $\mathrm{Pb} ; \mathrm{n}_{\mathrm{Cr}}-$ number of moles of $\mathrm{Cr}$ 
confidence limit $=0.710$ ). Since none of the suspected metal levels for A-yellow and B-Green paints was found as outliers, all the determinants of both the colours were retained.

According to Tables 4 and 5, there is an obvious tendency to have larger batchwise manufacturing variations and thus the products with different heavy metal levels in the consumer market. The consistency of results of $\mathrm{Pb}$ and $\mathrm{Cr}$ from the same batch clearly indicates the reliability of analysis procedures (Tables 1,2, 4 and 5). The high levels of $\mathrm{Pb}$ and $\mathrm{Cr}$ are inherent to the batch which may have been caused from impurities in the raw materials or some irregularities in the production process. Furthermore, it can be suggested that the $\mathrm{PbCrO}_{4}$ is present in yellow paints of brand A manufactured on 2014 March 27 and in green paints of brand B manufactured on 2014 January 13. The resulting $\mathrm{Pb}$ levels and $\mathrm{Cr}$ levels in all other paints can be due to small impurities in other paint components or contaminations during paint manufacturing.

On the other hand, A-Yellow and B-Green paints have been manufactured close to the Sri Lankan New Year season, the peak season when most of the paints manufactured are used, suggesting that manufactures would have increased production volumes with available raw materials without paying much attention to maintain the quality required due to the increased demand. This observation hence critically suggests the random use of $\mathrm{PbCrO}_{4}$ in certain paints by some of the manufactures. The label notations on paint containers that provide $\mathrm{Pb}$ content in the paint also have provided misleading information in some cases, because paints claiming 'SLS 539 ' and 'lead safe' notations contained the highest $\mathrm{Pb}$ and $\mathrm{Cr}$ levels.

From the rest of 31 samples, 10 had no detectable levels of $\mathrm{Pb}$, which include two white paints, four black paints, a yellow paint, two red paints and a brown paint. Brand D had four lead free paints while all the paints from brands $\mathrm{E}$ and $\mathrm{F}$ contained $\mathrm{Pb}$. Considering the low levels of $\mathrm{Pb}$ present in other 21 samples, out of which only three samples have exceeded the US standard, it is reasonable to presume that $\mathrm{Pb}$ in these paints originated from the raw materials, although in some cases, $\mathrm{Pb}$ may have been added to improve the quality of the paint within the safe limits in Sri Lanka. However, the $\mathrm{Pb}$ content of such paints is generally below $45 \mathrm{ppm}$. In 2014, Gottesfeld et al. studied $\mathrm{Pb}$ in new paints in Nepal and have suggested that unusually higher $\mathrm{Pb}$ levels are an indication of the presence of one or more intentionally added lead compounds during paint manufacturing. Considering the above fact, it is clear that the paints with considerable $\mathrm{Pb}$ and $\mathrm{Cr}$ levels tested may contain hazardous compounds that are intentionally added.

\section{Comparison of results with some other studies in Sri Lanka}

Results for enamel paints in studies by the Centre for Environmental Justice (CEJ), a Sri Lankan NonGovernmental Organization, are presented in Table 6.

From September 2012 to January 2013, the investigators have purchased 94 solvent-based enamel paint cans representing 57 brands sold in Sri Lankan market and have found that only $50 \%$ of the analysed paint samples had $\mathrm{Pb}$ levels below $600 \mathrm{ppm}$. A quarter of all paints analysed had $\mathrm{Pb}$ levels above $10000 \mathrm{ppm}$ and $37 \%$ of the samples contained very low Pb levels, below $90 \mathrm{ppm}$. They have also observed that 16 out of 22 of yellow samples, all of the 6 green samples and 12 out of 27 red samples contained $\mathrm{Pb}$ levels above $600 \mathrm{ppm}$. Ten out of 31 white paint samples contained $\mathrm{Pb}$ levels above 600 ppm (Rubesinghe et al., 2013).

A study on $\mathrm{Pb}$ levels in enamel paints conducted by CEJ in June 2015 has demonstrated that $43 \%$ of the analysed paint samples were below $90 \mathrm{ppm}$, whereas $54 \%$ of the analysed paint samples were below the 600 ppm regulatory limit. The highest $\mathrm{Pb}$ level found was

Table 6: $\mathrm{Pb}$ levels (on dry weight) in different colours of enamel paints

\begin{tabular}{lcccccccc}
\hline Colour & \multicolumn{3}{c}{$\begin{array}{c}\text { Rubesinghe et al. (2013) } \\
\text { Number of samples }\end{array}$} & $\begin{array}{c}\text { Max. Pb, } \\
\text { ppm }\end{array}$ & \multicolumn{3}{c}{ Nuthnamalala et al. (2015) } \\
& Total & $\geq 90 \mathrm{ppm}$ & $\geq 600 \mathrm{ppm}$ & Total & $\geq 90 \mathrm{ppm}$ & $\geq 600 \mathrm{ppm}$ & ppm \\
\hline White & 32 & 13 & 10 & 39000 & 10 & 1 & 0 & 520 \\
Green & 6 & 6 & 6 & 56000 & 11 & 10 & 5 & 44000 \\
Yellow & 22 & 18 & 10 & 129000 & 16 & 13 & 11 & 40000 \\
Red & 27 & 20 & 17 & 131000 & 18 & 7 & 6 & 13258 \\
\hline
\end{tabular}


$44000 \mathrm{ppm}$. Thus, researchers have found that paints with high $\mathrm{Pb}$ levels can be found in the market violating the legal standards (Rathnamalala et al., 2015).

When comparing the findings from above two studies with the current study, it reveals that there is a larger reduction of $\mathrm{Pb}$ levels in different colours from 2013 to 2015 , after the regulation came into effect. The biggest reduction between 2013 and 2015 can be seen in the white paints as all of the white paints either did not exceed 90 $\mathrm{ppm}$ or $600 \mathrm{ppm}$. However, one significant observation from data in Table 6 is that yellow and green paints tend to have higher $\mathrm{Pb}$ levels compared to other colours and still continue to be manufactured with exceedingly high $\mathrm{Pb}$ levels.

\section{Comparison of present study results with some recent international studies}

Although most countries have taken regulatory actions to eliminate the use of $\mathrm{Pb}$ in paints and the need for its worldwide ban has been emphasised, enamel paints with dangerously high $\mathrm{Pb}$ levels are still available in many countries. Gottesfeld et al. (2014) studied $\mathrm{Pb}$ levels in new paints in Nepal. A total of 75 paint samples have been purchased and analysed in 2012. Investigators found that $76 \%$ of all paints tested contained $\mathrm{Pb}$ levels greater than $90 \mathrm{ppm}$. According to the results reported, maximum $\mathrm{Pb}$ levels in analysed black, white, brown, red, green, and yellow paints were 6800, 16000, 19000, 67000,68000 and $200000 \mathrm{ppm}$, respectively. The highest $\mathrm{Pb}$ levels were found in yellow paints followed by green paints while black and white paints reported lower $\mathrm{Pb}$ levels (Gottesfeld et al., 2014).
In 2015, Environment and Social Development Organization (ESDO) in Bangladesh conducted research on $\mathrm{Pb}$ in new enamel paints. The researchers found that 43 of 56 red, yellow and white enamel paints analysed (77 \%) contained $\mathrm{Pb}$ levels above $90 \mathrm{ppm}$. Only thirteen of all samples analysed ( $23 \%$ ) contained $\mathrm{Pb}$ levels below $90 \mathrm{ppm}$. Thirty two of 38 red and yellow paints (84 \%) contained $\mathrm{Pb}$ levels greater than $90 \mathrm{ppm}$. Nineteen of all paints analysed (34\%) had dangerously high $\mathrm{Pb}$ levels greater than $10000 \mathrm{ppm}$. According to the results the reported highest $\mathrm{Pb}$ levels in analysed white, red, and yellow paints were 9600, 27000, and $85000 \mathrm{ppm}$, respectively. The highest $\mathrm{Pb}$ level was recorded in yellow paints and the researches have observed a least $\mathrm{Pb}$ level reduction in yellow paints with time compared to the $\mathrm{Pb}$ levels in other colours (ESDO, 2015)

Clark et al. studied $\mathrm{Pb}$ levels in enamel paints in Lebanon, Paraguay and Russia. All the analysed paint samples have been manufactured in 2011. They have found that $63 \%$ of all analysed paints contained $\mathrm{Pb}$ levels greater than $90 \mathrm{ppm}$, whereas $59 \%$ of paints exceeded the $600 \mathrm{ppm}$ limit and an average of $29 \%$ of samples contained exceedingly high $\mathrm{Pb}$ levels, $\geq 10000$ $\mathrm{ppm}$. The researchers have found that red and yellow paints contained much higher $\mathrm{Pb}$ levels compared to $\mathrm{Pb}$ levels in white paints. The highest $\mathrm{Pb}$ levels in white, red, and yellow paints, respectively were 2780,131000 , and 236000 ppm in Lebanon, 5100, 64600, and 169000 ppm in Paraguay and 3400, 35400, and 27200 ppm in Russia. Fifty-five (55\%) and $57 \%$ of red and yellow paints had reported $\mathrm{Pb}$ levels greater than $10000 \mathrm{ppm}$ (Clark et al., 2015). Maximum $\mathrm{Pb}$ levels reported in white, red, and yellow paints in each country along with the results from the current study are presented in Table 7.

Table 7: Highest $\mathrm{Pb}$ levels reported in white, red, and yellow enamel paints in different countries (Gottesfeld et al., 2014; Clark et al., 2015; ESDO, 2015).

\begin{tabular}{lcccccc}
\hline Colour & \multicolumn{6}{c}{ Highest Pb content, ppm on dry weight } \\
& $\begin{array}{c}\text { Lebanon, } \\
2011\end{array}$ & $\begin{array}{c}\text { Paraguay, } \\
2011\end{array}$ & $\begin{array}{c}\text { Russia, } \\
2011\end{array}$ & $\begin{array}{c}\text { Nepal, } \\
2012\end{array}$ & $\begin{array}{c}\text { Bangladesh, } \\
\text { 2015 }\end{array}$ & $\begin{array}{c}\text { Sri Lanka, } \\
2014\end{array}$ \\
\hline White & 2780 & 5100 & 3400 & 16000 & 96000 & 41 \\
Red & 131000 & 64600 & 35400 & 67000 & 27000 & 97 \\
Yellow & 236000 & 169000 & 27200 & 200000 & 85000 & 11545 \\
\hline
\end{tabular}

Comparison of research findings in different countries with the current study indicates the presence of much lower $\mathrm{Pb}$ levels in white, red, and yellow paints manufactured in Sri Lanka. It therefore suggests that
Sri Lanka is technologically advanced in manufacturing safe paints. However, some of the paint manufactures are still producing paints with high $\mathrm{Pb}$ levels, and the government as well as paint manufactures should take 
it as important to produce lead free paints in the whole of the Sri Lankan enamel paint industry. Although there is a large number of research studies carried out on $\mathrm{Pb}$ levels in enamel paints worldwide, there is a lack of data for $\mathrm{Cr}$ levels in enamel paints and consistency of the $\mathrm{Pb}$ and $\mathrm{Cr}$ levels through different production batches of manufacturers.

The Cadmium and Nickel levels in all the paints sampled for the current study were also analysed during this investigation but were not detected in any of the samples.

\section{CONCLUSION}

Results of the present study show that more than $94 \%$ of paints (34 samples out of 36 paint samples analysed) produced by branded manufactures in Sri Lanka adhered to safe standards without using high levels of unsafe $\mathrm{PbCrO}_{4}$. However, approximately $6 \%$ of enamel paints with high $\mathrm{Pb}$ and $\mathrm{Cr}$ levels were sold in Sri Lanka without considering the government regulations and safety concerns. $\mathrm{PbCrO}_{4}$ is present in yellow paints of brand $\mathrm{A}$ and green paints of brand $\mathrm{B}$ and is intentionally added to the different production batches. Therefore, it can be concluded that there are larger batchwise manufacturing variations in different production batches of some of the manufacturers. Finally, this study critically suggests that $\mathrm{Pb}$ and $\mathrm{Cr}$ containing compounds, especially $\mathrm{PbCrO}_{4}$ should be prioritised for substitution with safer raw materials available on the market. The need for formulating national policies to regularly monitor the quality of products before they reach the consumers and provide lead paint reformulation guidelines at nationallevel providing information about alternatives, their assessments and reformulation processes, is emphasized.

\section{Acknowledgements}

Authors express their gratitude to the Centre for Analytical Research and Development, Department of Chemistry, University of Colombo for providing laboratory support to this study.

\section{REFERENCES}

Abel A.G. (1999). Pigments for Paints. In: Paint and Surface Coatings - Theory and Practice (eds. R. Lambourne \& T.A. Strivens), pp 91 - 108. Woodhead/ Abington Hall, Abington, Cambridge CB1 6AH, England. Available at https://pdfs.semanticscholar.org/ f51f/17946c21c795690907980aed9124e04737bc.pdf, Accessed 18 August 2018.
Agency for Toxic Substances and Disease Registry (ATSDR) (2012). Toxicological Profile for Chromium. Available at https://www.atsdr.cdc.gov/toxprofiles/tp7.pdf, Accessed 01 August 2018.

Agency for Toxic Substances and Disease Registry (ATSDR) (2013). Priority List of Hazardous Substances. Available at https://www.atsdr.cdc.gov/spl/, Accessed 01 August 2018.

Agency for Toxic Substances and Disease Registry (ATSDR) (2020). Toxicological Profile for Lead. Available at https:// www.atsdr.cdc.gov/toxprofiles/tp13.pdf, Accessed 20 September 2020.

ASTM International (2009). Standard Test Methods for Low Concentrations of Lead, Cadmium and Cobalt in Paint by Atomic Absorption Spectroscopy, ASTM D 3335-85a.

ASTM International (2010). Standard Test Methods for Low Concentrations of Chromium in Paint by Atomic Absorption Spectrometry, ASTM D 3718-85a.

Brosché S., Denney V., Weinberg J., Calonzo M.C., Withanage H. \& Clark S. (2014). Asia Regional Paint Report. Available at https://rb.gy/fgiiak, Accessed 20 July 2018.

Clark C.S. et al. (15 authors) (2009). Lead levels in new enamel household paints from Asia, Africa \& South America. Environmental Research 109: 930-936.

Clark C.S., Speranskaya O., Brosche S., Gonzalez H., Solis D., Kodeih N., Roda S. \& Lind C. (2015). Total lead concentration in new decorative enamel paints in Lebanon, Paraguay and Russia. Environmental Research 138: 432 438.

Connora D.O., Houa D., Yeb J., Zhangc Y., Okd Y.S., Songa Y., Coulone F., Penga T. \& Tianf L. (2018). Lead-based paint remains a major public health concern: A critical review of global production, trade, use, exposure, health risk, and implications. Environment International 121: 85-121.

Consumer Affairs Authority (CAA) (2011). Sri Lanka Gazette Extra Ordinary No 1725/30. Available at http://www.caa. gov.lk/web/images/Direction/English/sec12/direction_36E. pdf, Accessed 04 August 2018.

Environment and Social Development Organization (ESDO) (2015). National Report on Lead in new enamel household paints of Bangladesh. Available at http://esdo.org/wpcontent/uploads/Bangladesh-National-Report-2015-Final. pdf, Accessed 10 August 2018.

Gottesfeld P., Pokhrel D. \& Pokhrel A.K. (2014). Lead in new paints in Nepal. Environmental Research 132: 70-75. DOI: http://dx.doi.org/10.1016/j.envres.2014.03.036

Gupta A. \& Gauri S.K. (2013). Determination of optimal quantities of different types of driers for addition in the batches of paint formulation. International Journal of Engineering, Science and Technology 5: 1-13.

DOI: http://dx.doi.org/10.4314/ijest.v5i4.1

Hossain M.L., Salam M.A., Das S.R., Hossain M.I., Nahida S.K.N, Mamun S.A., Talukder S. \& Khanam M. (2013). Lead content of enamel paints in leading paint companies in Bangladesh. IOSR Journal of Environmental Science, Toxicology and Food Technology 3(1): 48-53.

International Labor Office (ILO) (1921). Convention 13 concerning the use of white lead in painting. Available at shorturl.at/eAHPO, Accessed 04 August 2018. 
IPEN (2014). Eliminate lead paint - Protect children's health. Available at https://ipen.org/sites/default/files/documents/ ipen-booklet-lead-v1_3-web.pdf, Accessed 20 August 2018.

Jha P., Samal A.C., Santra S.C. \& Dewanji A. (2016). Heavy metal accumulation potential of some wetland plants growing naturally in the city of Kolkata, India. American Journal of Plant Sciences 07: 2112-2137. DOI: http:// dx.doi.org/10.4236/ajps.2016.715189

Kumar A. \& Gottesfeld P. (2008). Lead content in household paints in India. Science of the Total Environment 407: 333-337.

Meyer P.A., Brown M.J. \& Falk H. (2008). Global approach to reducing lead exposure and poisoning. Mutation Research 659: $166-175$.

Oligo J.K., Onditi A.O., Salim A.M. \& Yusuf A.O. (2017). Assessment of levels of heavy metals in paints from interior walls and indoor dust from residential houses in Nairobi city country, Kenya. Chemical Science International 21(1): $1-7$.

Philippines Department of Environment and Natural Resources (PDENR) (2013). Chemical control order (CCO) for lead and lead compounds. Available at https://chemical.emb. gov.ph/wp-content/uploads/2017/03/DAO-2013-24-CCOLead.pdf, Accessed 04 August 2018.

Rathnamalala E., Brosche S. \& Denny V. (2015). National Report: Lead in new household enamel paints in Sri Lanka. Centre for Environment Justice. Sri Lanka. Available at http://escrj.southasianrights.org/front/view_document/55, Accessed 20 July 2018.

Rubesinghe C., Brosche S., Denny V., Clark S. \& Weinberg J. (2013). National Report: Lead in Sri Lanka's New Enamel Household Paints. Centre for Environment Justice. Sri Lanka. Available at https://ejustice.lk/wp-content/ uploads/2017/10/Lead-paint-study-2013.pdf, Accessed 20 July 2018.

Rubesinghe C., Withanage H., Brosche S. \& Weinberg J. (2015). Lead Levels in Enamel Paints in Sri Lanka - Two
Years after the Regulation. Centre for Environment Justice in collaboration with IPEN, ARNICA.

Shim H.S., Lee Y.Y., Cho D.Y. \& Choi G.H. (2011). A study on R\&D process for an eco-friendly inorganic paint. Advanced Materials Research 368-373: 3816-3820.

DOI: https://doi.org/10.4028/www.scientific.net/amr.368373.3816

Singapore National Environmental Agency (NEA) (2014). List of controlled hazardous substances. Available at https:// www.nea.gov.sg/our-services/pollution-control/chemicalsafety/hazardous-substances, Accessed 04 August 2018.

Sri Lanka Standards Institution (SLSI) (2010). Specification for enamel paints (First Revision), SLS 539:2010.

U.S. Consumer product safety improvement act (CPSIA) (2008). Public Law 110-314. Available at http://www.cpsc. gov/cpsia.pdf, Accessed 04 August 2018.

United Nations Environment Program (UNEP) and World Health Organization (WHO) (2011). Operational Framework-Global Alliance to Eliminate Lead Paint. Available at www.who.int/ipcs/assessment/public_health/ framework.pdf, Accessed 14 August 2018.

Wani A.L., Ara A. \& Usmani J.A. (2015). Lead toxicity: A review. Interdisciplinary Toxicology 8(2): 55-64. DOI: https://doi.org/10.1515/intox-2015-0009

World Health Organization (WHO) (1995). Inorganic lead-Environmental Health Criteria 165, International Programme on Chemical Safety. Available at http://www. inchem.org/documents/ehc/ehc/ehc165.htm, Accessed 10 August 2018.

World Health Organization (WHO) (2010). Preventing disease through healthy environments-Exposure to lead: A major public health concern. Available at https://rb.gy/9m5lwq, Accessed 10 August 2018.

World Health Organization (WHO) (2017). Lead poisoning and health. Available at https://www.who.int/news-room/ fact-sheets/detail/lead-poisoning-and-health, Accessed 20 September 2020. 